\title{
Influence of different sample preparation strategies on the proteomic identification of stress biomarkers in porcine saliva
}

\author{
Ana Gutiérrez ${ }^{1}$, José Joaquín Cerón ${ }^{1}$, Ebrahim Razzazi-Fazeli², Sarah Schlosser ${ }^{2}$ and Fernando Tecles ${ }^{1 *}$ (D)
}

\begin{abstract}
Background: The influence of two different sample treatments comprising the enrichment of glycoproteins by boronic acid and dynamic range compression by hexapeptide libraries, on the detection of stress markers in saliva of pigs was evaluated in this study. For this purpose, saliva samples collected before and after the application of an acute stress model consisting of nasal restraining in pigs were processed without any treatment and with the two different treatments mentioned above. Protein separation by two-dimensional gel electrophoresis (2-DE) followed by identification of proteins using MALDI-TOF/TOF mass spectrometry (MS) was used as proteomic technique.

Results: The application of each of the two different sample treatment protocols allowed the identification of unique proteins that could be potential salivary acute stress markers in pigs: lipocalin 1, protein S100-A8 and immunoglobulin M by enrichment of glycoproteins; protein S100-A9, double headed protease inhibitor submandibular gland, and haemoglobin by dynamic range compression; and protein S100-A12 by both protocols. Salivary lipocalin, prolactin inducible protein, light chain of immunoglobulins, adenosine deaminase and carbonic anhydrase VI were identified as potential markers in untreated saliva as well as one of the other treatments.
\end{abstract}

Conclusion: The use of different procedures allowed the detection of different potential stress markers. Although from a practical point of view, the use of saliva without further treatment as well as the enrichment of glycoproteins are less expensive and easy to do procedures.

Keywords: Glycoprotein-enrichment, Hexapeptide libraries, Pig, Proteomics, Saliva

\section{Background}

Proteomics studies in saliva are gaining attention both in human and veterinary medicine, as the salivary proteome has the potential for detecting and identified biomarkers of stress and diseases [1].

Stress as an animal welfare alteration leads to considerable financial losses due to an increase in animal susceptibility to disease, a decrease in life expectancy, an impairment of growth and reproduction as well as a decrease in meat quality [2,3]. During the last 20 years the quantification of cortisol levels in saliva has been used for stress evaluation in porcine. In addition, other markers of stress such as chromogranin A ( $\mathrm{CgA})$,

\footnotetext{
*Correspondence: ftecles@um.es

${ }^{1}$ Department of Animal Medicine and Surgery, Regional Campus of International Excellence "Campus Mare Nostrum", Hospital Veterinario 4 planta, University of Murcia, 30100, Espinardo, Murcia, Spain

Full list of author information is available at the end of the article
}

immunoglobulin A, testosterone or $\alpha$-amylase have been measured in saliva $[4,5]$. However, there is only one report in which potential new porcine markers of stress are investigated by using proteomic approaches [6].

Dynamic range compression (DRC) by hexapeptide libraries and enrichment of glycoproteins by boronic acid are techniques that have been used for sample enrichment. Both procedures have been applied to human saliva [1, 7]. The dynamic range compression could help to detect potential low-abundance markers which are masked by a subset of abundant proteins that are detected and accurately quantified with traditional sample treatment [8]. On the other hand, enrichment by boronic acid was selected since previous works have confirmed it as a valid non-destructive glycoprotein enrichment methodology for complex samples such as whole saliva in humans [7]. It consists on the 
covalent reaction between boronic acid and cis-diols to form five- or six-membered cyclic esters in alkaline aqueous solution [9] and it is useful for capturing glycosylated molecules from highly complex sample with intact glycan structures [10]. Enrichment of glycoproteins could increase the sensitivity in the detection of carbohydrate-based markers. To the authors' knowledge, there are no previous studies that had explored specifically glycoproteins in saliva as markers of acute stress. However, glycoproteins have been proven to be altered in cultured cells subjected to acute heat stress [11] and disease conditions in vivo such as neoplasms [12].

The objective of this study was to evaluate how the enrichment of glycoproteins using the phenyl boronic acid (PBA) ligand or DRC by hexapeptide libraries could affect the identification of acute stress markers in porcine saliva. For this purpose, these two techniques were applied to aliquots of saliva collected before and after the application of an acute stress model consisting of nasal restraining, and the results were further compared with aliquots of untreated saliva collected the same way but where these techniques were not applied. The saliva samples were analysed by two dimensional gel electrophoresis (2-DE) and differentially altered proteins were identified.

\section{Methods}

\section{Animals and sampling procedure}

Saliva samples of animals subjected to snaring restraint were obtained from 25 pigs of a farm located in the South East of Spain. All animals were males of the commercial crossbred Duroc $\mathrm{x}$ (Landrace $\mathrm{x}$ Large White) and around 3 to 4 months of age. The pigs were given access ad libitum to water and a diet formulated according to the $\mathrm{CP}$ standards recommended by the Spanish Foundation for the Development of Animal Nutrition (Fundación Española para el Desarrollo de la Nutrición Animal 2013. Necesidades nutricionales para ganado porcino. Normas FEDNA. Madrid, Spain. http:// www.fundacionfedna.org/sites/default/files/NormasPORCINO_2013rev2.pdf), with $155 \mathrm{~g} \mathrm{CP} / \mathrm{kg}$ and $13.59 \mathrm{MJ}$ of metabolizable energy $/ \mathrm{kg}$. They were housed in pens with a minimum space of $0.65 \mathrm{~m}^{2}$ per animal (Council of Europe. ETS 123. Strasbourg, France: The Council; 1986. [Last accessed January 5, 2014]. European Convention for the Protection of Vertebrate Animals Used for Experimental and Other Scientific Purposes. http://conventions.coe.int/treaty/en/treaties/html/123.htm) and an average temperature of $23 \pm 2{ }^{\circ} \mathrm{C}$.

The pigs were subjected to snaring restraint by using a nose sling according to previous studies [4]. Saliva samples were obtained before (T0) and after 15 min (T15) of the snaring restraint stimuli by allowing the pig to chew sponges for 2-3 min followed by centrifugation of sponge-containing salivette tubes (Sarstedt, Aktiengesellschaft \& Co. Nümbrecht, Germany). Two pools of saliva samples of around $50 \mathrm{~mL}$ were prepared for T0 and T15 time points, respectively. Each pool was prepared by mixing $2 \mathrm{~mL}$ of saliva per animal at the same time point.

\section{Biochemical stress characterization}

For animal stress monitoring $\mathrm{CgA}$ and cortisol levels were quantified in saliva samples. An in-housed developed time-resolved immunofluorometric assay was used for CgA quantifications according to the instructions reported earlier [13]. The coefficients of variation were $6.23 \%$ and $5.82 \%$, for intra-assay and inter-assay precision, respectively. The limit of quantification was $0.024 \mu \mathrm{g} / \mathrm{mL}$.

Salivary cortisol measurements were performed using an adaptation of an automated chemiluminescent immunoassay developed for human serum cortisol measurements to porcine saliva [14]. Intra- and inter-assay coefficients of variation were lower than $16 \%$, and the limit of detection was $0.19 \mathrm{ng} / \mathrm{mL}$.

The individual concentrations of $\mathrm{CgA}$ and cortisol in saliva samples were $\log$ transformed for statistical analysis. Afterwards, an unpaired t test was applied to compare the levels of $\mathrm{CgA}$ and cortisol at T0 and T15 using specific statistical software (GraphPad Prism 5, GraphPad Software Inc., La Jolla, United States). The level of significance was set at $P<0.05$.

\section{Sample preparation protocols}

The total protein content of the two saliva pools (corresponding to T0 and T15 minutes) was quantified according to Bradford method. Earlier, 3 different sample treatment protocols were performed (Fig. 1). For the sample protocol 1 (SP1), that corresponded to the untreated saliva, three replicates of each salivary pool with $30 \mu \mathrm{g}$ of total protein were lyophilized and stored at $-80{ }^{\circ} \mathrm{C}$.

For the sample protocol 2 (SP2), $1 \mathrm{mg}$ of total protein from each salivary pool was lyophilized and subjected to PBA treatment. A commercial glycoprotein enrichment kit based on PBA matrix was used (NuGel ${ }^{\mathrm{m}} \mathrm{G}$ Glycoprotein enrichment PBA kit, Biotech Support Group, New Jersey, USA) according to the manufacturer's instructions. In brief, the freeze-dried PBA saliva prepared of each pool was dissolved in $250 \mu \mathrm{L}$ of binding buffer, added to $50 \mathrm{mg}$ of PBA matrix and incubated for $10 \mathrm{~min}$. The unbound fraction was discarded after centrifugation for $3 \mathrm{~min}$ at $12.750 \mathrm{~g}$. After washing the matrix three times with $350 \mu \mathrm{L}$ of wash buffer for $5 \mathrm{~min}$, the glycoprotein-enriched fraction was obtained by incubation of the matrix with $300 \mu \mathrm{L}$ of sorbitol elution 


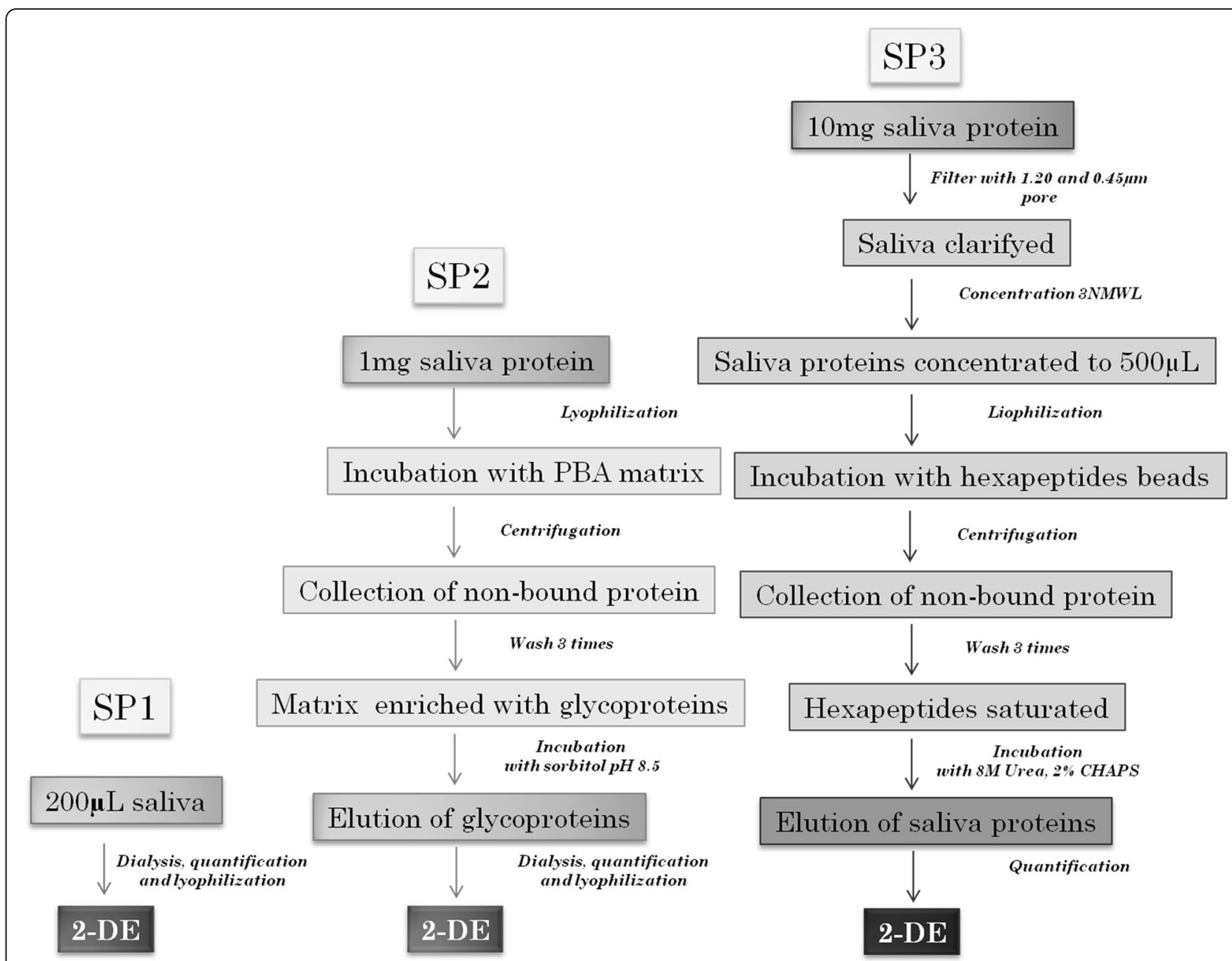

Fig. 1 Flowchart of the sample preparation protocols used prior to 2DE-MS analysis for the identification of stress biomarker. SP1: sample preparation 1 (untreated saliva), SP2: sample preparation 2 (glycoprotein enrichment), SP3: sample preparation 3 (dynamic range compression)

buffer for 10 min followed by centrifugation at $12750 \mathrm{x}$ $\mathrm{g}$ for $3 \mathrm{~min}$ and stored at $-80{ }^{\circ} \mathrm{C}$ until analysis.

For the third protocol (SP3), $25 \mathrm{~mL}$ of saliva from each pool were first filtered using $1.20 \mu \mathrm{m}$ and $0.45 \mu \mathrm{m}$ pore size filters, respectively, and then concentrated to 500 $\mu \mathrm{L}$ with centrifugal filter devices of $3 \mathrm{kDa}$ (Amicon Ultra-15, Millipore Corporation, Billerica). Filtration was required since the high level of concentration of the saliva produces the concentration of very small particles of food debris and other saliva components. This protocol was adapted from previous studies [15]. Afterwards, $500 \mu \mathrm{L}$ of each concentrated pool was lyophilized and subjected to treatment using a commercial kit for DRC (Proteominer Small-Capacity kit, Bio-Rad Laboratories, California, USA) according to the manufacturer's instructions. In brief, $10 \mathrm{mg}$ of total protein was loaded to beads containing a diverse library of combinatorial peptide ligands. After an incubation of two hours at room temperature in a rotational shaker followed by three washing steps with PBS, proteins were eluted in three consecutive steps through incubation of the beads for 15 min with $20 \mu \mathrm{L}$ of elution reagent (8 M Urea, 2\% CHAPS) followed by centrifugation at $1.000 \mathrm{~g}$ for $1 \mathrm{~min}$. The eluate was stored at $-80{ }^{\circ} \mathrm{C}$ until analysis.

\section{Two dimensional gel electrophoresis (2DE)}

Three replicated gels were performed for each time point in each different sample protocol. For proper comparisons, the same protein amount, $15 \mu \mathrm{g}$ of total protein was used for all the protocols investigated in this study. The corresponding volume of each sample was subjected to lyophilization in triplicates and the pellets were solubilized in rehydration sample buffer $(8 \mathrm{M}$ urea, 2\% CHAPS, 2\% IPG Buffer, 20 mM DTT). Isoelectric focusing was performed according to the manufacturer's instructions in $11 \mathrm{~cm} \mathrm{pH} \mathrm{3-11} \mathrm{NL} \mathrm{IPG} \mathrm{strips} \mathrm{(Immobi-}$ line Dry Strip, GE Healthcare Bio-Sciences, Uppsala, Sweden). For the second dimension, IPG strips were first 
equilibrated for $10 \mathrm{~min}$ in 2D-equilibration buffer containing 2\% dithiothreitol followed by incubation for $5 \mathrm{~min}$ in 2D-equilibration buffer containing $2.5 \%$ of iodoacetamide. Electrophoresis was carried out in homemade gradient $10-15 \%$ polyacrylamide gels of $140 \mathrm{~mm} \times 140 \mathrm{~mm} \times$ $1.5 \mathrm{~mm}$ at $15{ }^{\circ} \mathrm{C}$ and $25 \mathrm{~mA}$ /gel. For overall pattern view (analytical gels) and MS analysis (preparative gels), gels were respectively classical and mass compatible silver stained, according to general protocols [16].

2-DE gels were digitalized using an ImageScanner II (GE Healthcare Life Sciences, Uppsala, Sweden) and evaluated by using specific software (Image Master 2D Platinum 7.0, GE Healthcare Life Sciences, Uppsala, Sweden). Gel evaluation consisted of spot detection and matching of protein patterns of three replicated gels of each time point in each different sample protocol. Volumes of single spots were normalized onto the overall spot volume of all spots and thus expressed as \% volume. An unpaired t test with Welch's correction which does not assume equal SDs was used to evaluate spot concentration differences between $\mathrm{T} 0$ and $\mathrm{T} 15$ in all protocols with specific statistical software (GraphPad Prism 5, GraphPad Software Inc., La Jolla, United States). The level of significance was set at $P<0.05$.

\section{Protein identification}

Spots that appeared differentially regulated in the different timepoints studied (T0 and T15) were initially identified as compared to identifications of spots obtained in the same positions of the gel in previous studies $[17,18]$. In case of no annotation or no correspondence, spots were excised from preparative gels and sent to the VetCore Facility for Research (University of Veterinary Medicine of Vienna, Austria) for protein identification.

2D-spots were washed and destained, followed by reduction with dithiotreitol and subsequent alkylation with iodoacetamide [19]. In-gel digestion with trypsin (Trypsin Gold, Mass Spectrometry Grade, Promega, Madison, WI) was performed as described elsewhere [20]. Peptides were extracted in three consecutive steps with $30 \mu \mathrm{l}$ of $5 \%$ trifluoroacetic acid in $50 \%$ aqueous acetonitrile supported by ultrasonication for $10 \mathrm{~min}$, respectively. Subsequently, a vacuum concentrator (Eppendorf, Hamburg, Germany) was used to dry down extracted peptides. In order to concentrate and desalt the dried peptides, $\mathrm{C}_{18}$ Zip Tips (microbed) (Millipore, Billerica, MA) were used according to the manufacturer's instructions.

Peptides $(0.5 \mu \mathrm{l})$ were mixed 1:1 with matrix consisting of saturated $\alpha$-cyano-4-hydroxycinnamic acid (PAC target Bruker Daltonics, Bremen, Germany) in aqueous acetonitrile and $0.1 \%$ trifluoroacetic acid $(30: 70, v / v)$, and spotted onto a ground steel target plate. Data were acquired in MS and MS/MS modes on a MALDI-TOF/
TOF mass spectrometer (Ultraflex II, Bruker Daltonics, Bremen Germany). Spectra processing and peak annotation were carried out using FlexAnalysis 3.0 and Biotools 3.2 (both Bruker Daltonics, Bremen, Germany).

Processed spectra were searched via Mascot and the software ProteinScape 2.1 (Bruker Daltonics, Bremen Germany) in the UniProt database (taxonomy 'Sus scrofa') and the NCBI database (taxonomy 'all entries') using the following search parameter: fixed modification carbamido-methylation on cysteine; variable modifications deamidation on asparagine and glutamine, oxidation on methionine as well as formation of pyroglutamic acid; enzyme specifity trypsin; charge state $\mathrm{z}=$ 1 , MS tolerance $100 \mathrm{ppm}$; MS/MS tolerance $1 \mathrm{Da}$; one missed cleavage allowed. Protein identifications were considered statistically significant where $p<0.05$ and scores $\geq 60$ as we have reported in previous studies [17].

\section{Results}

\section{Biochemical stress characterization}

The results of the acute stress markers quantified in saliva samples of pigs subjected to the experimental stress stimuli appear in Fig. 2. A statistically significant increase was observed after 15 min of the stressor application in comparison to the basal level for both biomarkers, CgA (1.43-fold, $p=0.0077)$, and cortisol (1.30-fold, $p=0.0342$ ). Results obtained for the pooled saliva samples at T0 vs. T15 were 0.72 vs. $1.04 \mu \mathrm{g} / \mathrm{mL}$ for CgA, and 0.37 vs. $0.51 \mathrm{ng} / \mathrm{mL}$ for cortisol.

\section{Sample preparation protocols comparison}

The amount of original pooled saliva sample needed to perform the complete analysis was completely different between protocols. For SP1, which corresponds to untreated saliva, a volume of $54 \mu \mathrm{L}$ of each pooled saliva sample was used. In contrast, $1.2 \mathrm{~mL}$ of each pooled

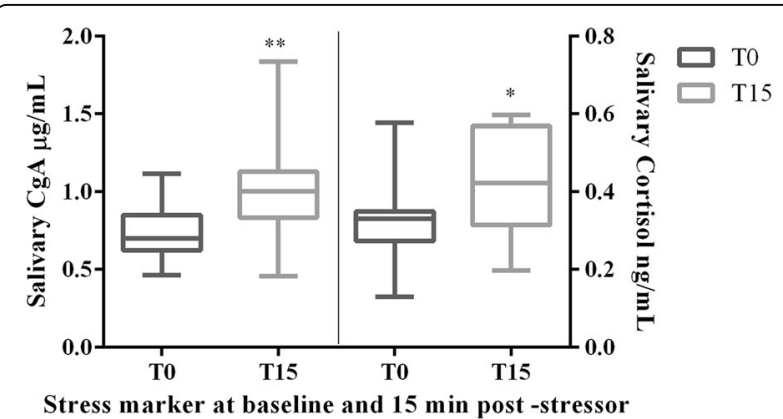

Fig. 2 Concentrations of chromogranin A $(\mathrm{CgA})$ and cortisol $(\mu \mathrm{g} / \mathrm{mL}$ or $\mathrm{ng} / \mathrm{mL})$ in saliva samples of pigs $(n=25)$ before (T0) and after 15 min (T15) of being subjected to a stress model of nose snaring. The plot shows median (line within box), 25th and 75th percentiles (box), 5th and 95th percentiles (whiskers) and outliers $\left(^{\circ}\right)$. Asterisk represents the statistically significant differences from each group. *level of significance $P<0.05$. ${ }^{* *}$ level of significance $P<0.01$ 
saliva was needed for SP2 and $25 \mathrm{~mL}$ for SP3 protocols. The mean $\%$ of the total amount of protein recovery was $5.9 \%$ and $1.2 \%$ for SP2 and SP3, respectively.

The time spent to perform each protocol was similar, oscillating between 13 and $19 \mathrm{~h}$. However, the labour invested was different since sample preparation in SP1 required $12 \mathrm{~h}$ of dialysis and $3 \mathrm{~h}$ of lyophilization (total $15 \mathrm{~h}$ ). In contrast, SP2 needed two lyophilization steps of $3 \mathrm{~h}, 12 \mathrm{~h}$ of dialysis and $50 \mathrm{~min}$ for the enrichment of glycoproteins - a multistep procedure with several incubations and centrifugations (total $19 \mathrm{~h}$ ). To perform SP3, a filtration step was needed, followed by $5 \mathrm{~h}$ of saliva concentration, a lyophilization step of $5 \mathrm{~h}$, and $3 \mathrm{~h}$ for the DRC of proteins, a multistep procedure with several incubations and centrifugations (total $13 \mathrm{~h}$ ).

\section{Proteomic analysis comparison}

Figure 3 shows gel images obtained with SP1 (a), SP2 (b) and SP3 (c) protocols in basal (1) versus stress (2) conditions. Untreated saliva contained the most abundant proteins within this fluid (Figure $3 \mathrm{a}_{1}$ ). SP2 depleted nonglycosylated proteins which resulted in the disappearance of several 2D-spots and the appearance of some new 2D-spots in the more acidic $\mathrm{pH}$ range that were previously undetectable in untreated saliva (Figure $3 b_{1}$ ). SP3 showed also new spots that were not detectable in untreated saliva (Figure $3 \mathrm{c}_{1}$ ). The comparison between the gel images obtained in basal versus stress (Figure $3 \mathrm{a}_{2}, \mathrm{~b}_{2}$ and $\mathrm{c}_{2}$ ) conditions showed similar number of matched 2D-spots in the case of SP1 and SP2 (83 and 84 , respectively). However, only 23 matched 2D-spots were observed when SP3 was used.

The three protocols allowed the identification of several proteins that could be considered as potential markers of acute stress in porcine saliva (Fig. 4, Tables 1 and 2). By applying the SP1 protocol, various proteins differentially regulated in stress vs. basal conditions were successfully identified. These proteins were salivary lipocalin (5 spots), light chain of immunoglobulins (4 spots), prolactin inducible protein (3 spots), adenosine deaminase ( 3 spots) and carbonic anhydrase VI (1 spot). The application of SP2 protocol revealed prolactin inducible protein $(1 \mathrm{spot})$, salivary lipocalin (1 spot) and carbonic anhydrase (1 spot) as differentially regulated proteins in compliance with the SP1 protocol, as well as four proteins not detected with other protocols: lipocalin 1 (1 spot), immunoglobulin M (1 spot) and protein S100-A12 and A8 (1 spot each). Finally, in SP3 adenosine deaminase (1 spot) and light chain of immunoglobulins (1 spot) were obtained to be differentially regulated in stress vs. basal as in SP1, and protein S100-A12 as in protocol SP2. In addition, performing SP3 enabled the identification of three proteins that were not differentially regulated in the other two protocols, specifically protein S100-A9 (2 spots), double headed protease inhibitor submandibulary gland (1 spot) and haemoglobin (1 spot).

Data about the regulation of the proteins that were found differently expressed before and after the stress

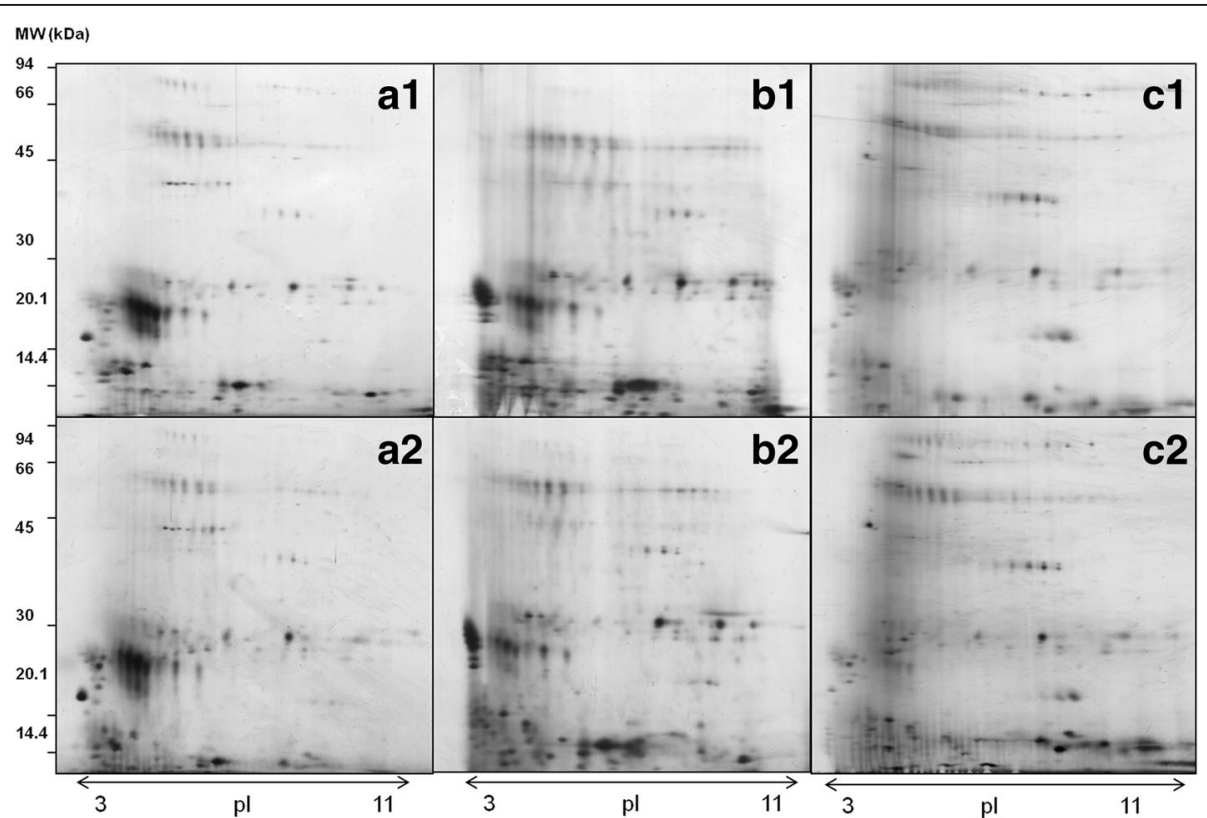

Fig. 3 Representative images of the salivary protein patterns obtained by 2-DE after three different sample preparation approaches, SP1 (untreated saliva, a), SP2 (glycoprotein enrichment, b), SP3 (dynamic range compression, c) on saliva samples from animals at T0 (1) and T15 (2) after being subjected to a stress model of nose snaring 


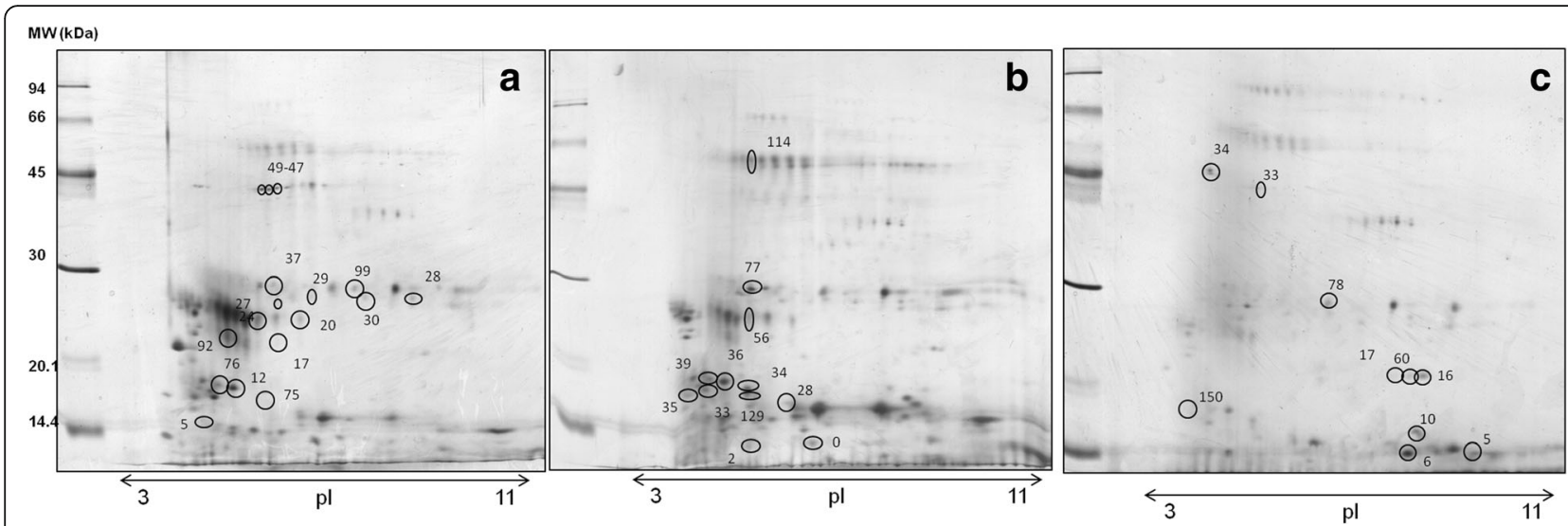

Fig. 4 Representative images of the 2D-spots successfully identified (circles) by MALDI-TOF/TOF MS or western blot from salivary protein patterns obtained in SP1 (a) SP2 (b) and SP3 (c). Numbering corresponds with data in Tables 1 and 2

application appear in Table 3. The proteins that are upregulated after stress were light chain of immunoglobulins, carbonic anhydrase VI, protein S100-A12, protein S100-A8, double headed protease inhibitor submandibulary gland and haemoglobin. On the other hand, the proteins that appeared down-regulated after stress in comparison to basal conditions were prolactin inducible protein, salivary lipocalin, adenosine deaminase, protein S100-A9, lipocalin 1 and immunoglobulin M.

\section{Discussion}

Saliva presents a large protein complexity with proteins from several different origins such as salivary glands secretions, plasma filtrates, cellular and bacterial derivatives, bronchial and gastrointestinal fluids and others. Moreover, many informative analytes are generally present in low amounts and the protein profile of saliva is dominated by subset of abundant proteins. Thus to improve detection and visibility of proteins expressed at lower levels in saliva, several depletion strategies has been reported such as enzyme-substrate depletion, immune-depletion or combinatorial peptide ligand library in humans [8]. Moreover, it has been reported that disease specific glycoprofile changes of a specific protein or protein subset are considered to better reflect given physiologic condition compared to an overall dysregulation of a particular protein [21]. However, the specific enrichment and purification of glycoproteins/glycopeptides is essential prior to mass spectrometric analysis since some glycoproteins are found in low abundance [22]. Taken into account all the statements detailed above, the use of techniques for dynamic range compression or glycoprotein profile of saliva seems to be of value for increasing the discovery of salivary markers and has been applied in the present study in pigs for stress biomarker identification and compared to untreated saliva. A homogeneous population of animals with similar sex, age and weight was used in order to minimize interindividual variability.

Pooled salivary samples from animals subjected to restrain stress at different time points, basal (T0) and stress peak (T15), were used in this study. The increased concentrations of $\mathrm{CgA}$ and cortisol at T15 indicated that the experimental model used was suitable to produce stress, as it has been previously described [13].

The main differences between the sample treatment protocols used in the present study were the amount of initial sample $(54 \mu$ lin SP1 vs. $25 \mathrm{~mL}$ in SP3) and the labour (SP1 being less complex than SP3) required for completing the treatments. In our study, a protocol for glycoprotein enrichment was applied using a commercial PBA resin as described for human saliva [7]. Moreover, the use of DRC by hexapeptide libraries has been successfully applied to human saliva using the same reagents as in our study [1].

The application of three different protocols for processing samples enabled the detection of a total of 12 proteins that showed significant changes in expression before and after stress. However, only three proteins were observed in SP1 and SP2 simultaneously (prolactin inducible protein, salivary lipocalin and carbonic anhydrase VI), two in SP1 and SP3 (adenosine deaminase and light chain of immunoglobulins) and one in SP2 and SP3 (protein S100-A12). The remaining 6 proteins suggested as markers of stress were reported according to the results of only one protocol (lipocalin 1, protein S100-A8 and immunoglobulin $\mathrm{M}$ in SP2; and protein S100-A9, double headed protease inhibitor and haemoglobin in SP3). The reason why none of the markers proposed in the study appeared in all three protocols simultaneously is very likely the targeted nature of the applied SP2 and SP3 protocols as in SP2 the main proteins which were detected are the glycosylated ones whereas in SP3 low 
Table 1 Identification of 2D-spots which appeared differentially regulated under stress (T15) in comparison to basal levels (T0) from pooled saliva samples of pigs subjected to snaring restraint

\begin{tabular}{|c|c|c|c|c|c|}
\hline Sample preparation & Spot number & Mean T0 & Mean T15 & $P$ value & Protein identification $^{a}$ \\
\hline \multirow[t]{17}{*}{ SP1 } & 5 & 0.23 & 1.05 & 0.0001 & Prolactin inducible protein \\
\hline & 20 & 0.53 & 1.07 & 0.0011 & Salivary lipocalin ${ }^{c}$ \\
\hline & 76 & 1.68 & 0.99 & 0.0011 & Prolactin inducible protein ${ }^{c}$ \\
\hline & 49 & 0.39 & 0.28 & 0.0050 & Adenosine deaminase \\
\hline & 48 & 0.29 & 0.21 & 0.0064 & Adenosine deaminase \\
\hline & 30 & 0.13 & 0.20 & 0.0089 & Light chain of immunoglobulins ${ }^{b}$ \\
\hline & 29 & 0.14 & 0.44 & 0.0148 & Light chain of immunoglobulins ${ }^{b}$ \\
\hline & 75 & 0.04 & 0.61 & 0.016 & No identification \\
\hline & 24 & 2.85 & 1.45 & 0.0218 & Salivary lipocalin \\
\hline & 47 & 0.24 & 0.15 & 0.0219 & Adenosine deaminase \\
\hline & 17 & 0.18 & 0.52 & 0.0243 & Salivary lipocalin \\
\hline & 99 & 0.22 & 0.15 & 0.0295 & Light chain of immunoglobulins ${ }^{b}$ \\
\hline & 27 & 0.20 & 0.50 & 0.0353 & Salivary lipocalin \\
\hline & 37 & 0.31 & 0.58 & 0.0385 & Carbonic anhydrase VI \\
\hline & 92 & 2.97 & 1.30 & 0.0405 & Salivary lipocalin \\
\hline & 12 & 1.62 & 1.02 & 0.0421 & Prolactin inducible protein ${ }^{c}$ \\
\hline & 28 & 0.14 & 0.26 & 0.0481 & Light chain of immunoglobulins ${ }^{b}$ \\
\hline \multirow[t]{12}{*}{ SP2 } & 34 & 0.21 & 0.86 & 0.0006 & No identification \\
\hline & 129 & 0.13 & 0.13 & 0.0007 & No identification \\
\hline & 36 & 1.80 & 1.15 & 0.0032 & Prolactin inducible protein ${ }^{c}$ \\
\hline & 28 & 0.25 & 0.16 & 0.0046 & No identification \\
\hline & 0 & 0.63 & 0.42 & 0.0053 & Protein S100-A12 \\
\hline & 77 & 0.53 & 0.83 & 0.0068 & Carbonic anhydrase VI \\
\hline & 35 & 2.59 & 1.9 & 0.0104 & Lipocalin 1 \\
\hline & 38 & 1.10 & 0.45 & 0.0139 & Prolactin inducible protein \\
\hline & 56 & 1.42 & 0.86 & 0.0161 & Salivary lipocalin \\
\hline & 2 & 0.42 & 0.64 & 0.0379 & Protein S100-A8 \\
\hline & 114 & 0.31 & 0.18 & 0.0410 & Immunoglobulin M \\
\hline & 33 & 1.40 & 0.62 & 0.043 & No identification \\
\hline \multirow[t]{11}{*}{ SP3 } & 10 & 0.77 & 1.79 & 0.0002 & $\begin{array}{l}\text { Double headed protease inhibitor } \\
\text { submandibular gland }\end{array}$ \\
\hline & 6 & 1.76 & 3.55 & 0.0006 & Protein S100-A12 \\
\hline & 136 & 0.09 & 0 & 0.0020 & No identification \\
\hline & 60 & 1.13 & 0.68 & 0.0092 & Protein S100-A9 \\
\hline & 5 & 1.10 & 2.00 & 0.0101 & Hemoglobin ${ }^{c}$ \\
\hline & 16 & 2.10 & 1.23 & 0.0104 & Protein S100-A9 \\
\hline & 33 & 0.33 & 0.15 & 0.0170 & Adenosine deaminase \\
\hline & 78 & 0.85 & 0.62 & 0.0260 & Light chain of immunoglobulins ${ }^{b}$ \\
\hline & 150 & 0.90 & 0.25 & 0.0318 & No identification \\
\hline & 34 & 0.34 & 0.71 & 0.0326 & No identification \\
\hline & 17 & 0.59 & 0.36 & 0.0463 & No identification \\
\hline
\end{tabular}

SP1: sample preparation 1, untreated pooled saliva. SP2: sample preparation 2, glycoprotein enrichment fraction of pooled saliva samples. SP3: sample preparation 3 , dynamic range compression of pooled saliva samples

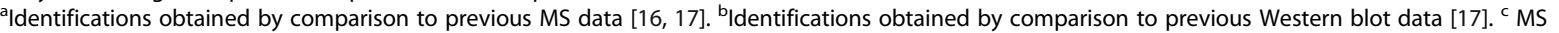
identifications performed in the present study (Table 2) 


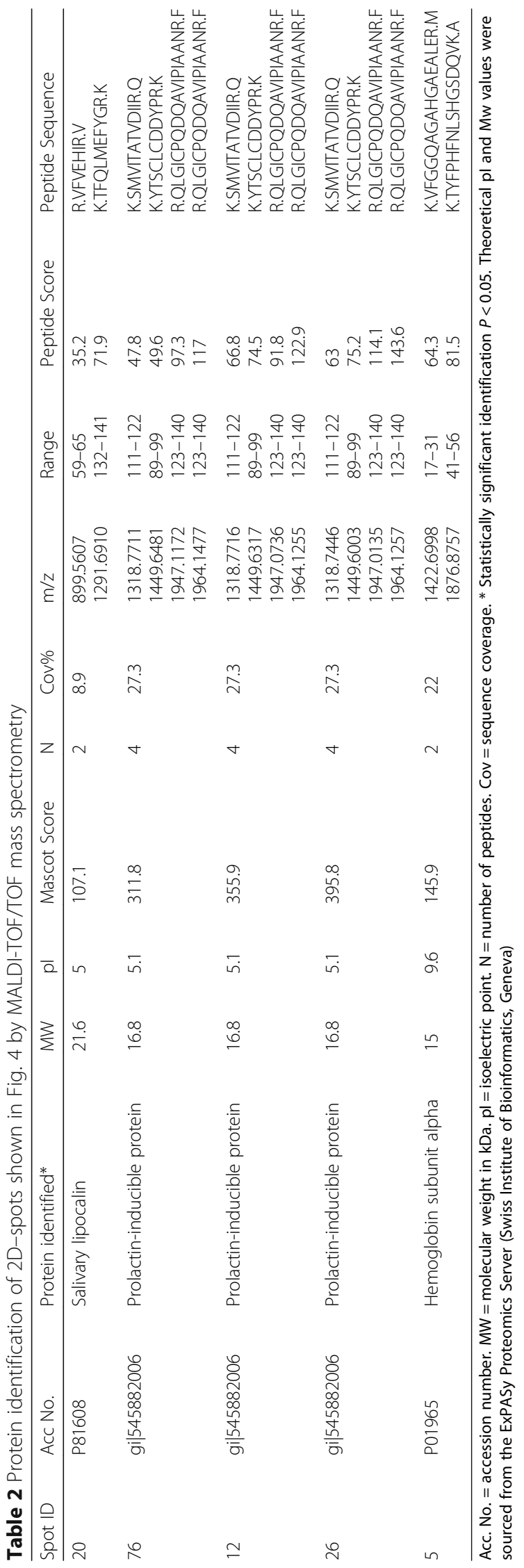


Table 3 Differential expression of proteins successfully identified by MS analysis under stress conditions in porcine saliva samples subjected to different sample preparation protocols

\begin{tabular}{|c|c|c|c|c|}
\hline Protein name & Mean Basal (T0) & Mean Stress (T15) & Regulation & Number of spots identified \\
\hline Salivary lipocalin & 1.36 & 0.95 & Down & 6 \\
\hline Prolactin inducible protein & 1.29 & 0.94 & Down & 5 \\
\hline Light chain Igs & 0.30 & 0.34 & Up & 5 \\
\hline Adenosine deaminase & 0.31 & 0.20 & Down & 4 \\
\hline Carbonic anhydrase VI & 0.43 & 0.71 & Up & 2 \\
\hline Protein S100-A12 & 1.20 & 1.99 & Up & 2 \\
\hline Protein S100-A9 & 1.08 & 0.97 & Down & 2 \\
\hline Lipocalin 1 & 2.60 & 1.97 & Down & 1 \\
\hline Protein S100-A8 & 0.43 & 0.65 & Up & 1 \\
\hline $\lg M$ & 0.31 & 0.18 & Down & 1 \\
\hline Double headed protease inhibitor submandibular gland & 0.77 & 1.79 & Up & 1 \\
\hline Haemoglobin & 1.10 & 2.00 & Up & 1 \\
\hline
\end{tabular}

abundant proteins predominate. It is important to note that even when using the same samples, not only different sample treatment protocols but also different mass spectrometry platforms produced completely different biomarker profiles, and therefore more than one analytical proteomic platform can be employed for wide the range of biomarkers detection [23].

All proteins identified in the present study could be considered as novel potential markers of acute stress in pigs, although none of these proteins were identified in a previous investigation in which changes of the saliva proteome of pigs were studied under different acute stress stimuli [6]. These differences could be explained by the application of different proteomic approaches, including sample preparation and staining of 2D-gels [16] as well as by the different stressor applied to the animals [24]. In contrast, some of them (salivary lipocalin, lipocalin 1, double headed protease inhibitor protein, adenosine deaminase, proteins S100-A8, S100-A9 and S100-A12) were previously described as potential markers of porcine systemic disease using conventional proteomic approaches [17]. Lipocalins are involved in immune response modulation and regulation of cell homeostasis [25]. S100A8, S100A9, and S100A12 are predominantly expressed in phagocytes and are strongly associated with pro-inflammatory functions, inducing chemotaxis, neutrophil adhesion and secretion of proinflammatory mediators [26, 27]. All these proteins, as well as double headed protease inhibitor, are overexpressed in saliva of pigs with systemic disease [17], but to the authors' knowledge little information is available about the function of this proteins under stress conditions.

Adenosine deaminase is an enzyme considered as a biomarker of cell mediated immunity [28] since increases in serum due to cell damage [29] or increase in the number of $\mathrm{T}$ lymphocytes [30]. It is also present in saliva and increases in oral diseases such as squamous cell carcinoma of the tongue [31]. In pigs, salivary adenosine deaminase is up-regulated due to systemic inflammation [17]. Carbonic anhydrase VI is the only isozyme of the carbonic anhydrase family that is secreted in saliva [32]. It participated in several functions such as ion transport, secretory processes and saliva production, regulation of the $\mathrm{pH}$ and buffering capacity of the saliva [33], olfaction and taste [34, 35]. A relationship between its secretion and the sympathetic nervous system has been reported [34]; although no increase was detected in pigs after acute stress [36] but in pigs with systemic disease [17].

Prolactin inducible protein in saliva is involved in immune regulation in the mouth, having a role in tumor progression, preventing bacterial adhesion and infection [37]. An increase of this protein in saliva has been reported in humans after acute stressor [38]. Salivary IgM derives from crevicular fluid or from plasma leakage [39]. An increase on IgM titre, as well as IgA and IgG, has been reported due to psychological stress in students [40]; so it could be a potential stress marker. Light chains of immunoglobulin interact with neutrophils and mast cells, stimulating chronic inflammation via activation of specific immune cells [41]. No reports have been found light chains of immunoglobulins in saliva and stress, although a decrease has been reported after physical exercise in humans [42].

\section{Limitations}

This study has some limitations that need to be discussed. Ideally reproducibility studies of the protocols should have been performed. This is especially important in SP2 and SP3 where a pretreatment of the sample were performed and the lack of replication might bias 
the results somewhat. Budget limitations and the high amount of saliva required for the SP3 procedure did not allow us to do these studies. Overall without these reproducibility studies the results should be taken with caution.

Another limitation related to SP2 protocol is that a specific staining for glycoproteins was not performed to ensure the usefulness of the PBA for enriching glycoproteins, since we did not have enough sample volume left after performing the analytical protocols. However several reports have demonstrared that boronic acid is adequate for glycoproteins enrichment prior mass analysis $[10,43]$. In addition regarding SP3, this protocol produces a loss in the protein detected, since very high abundance proteins quickly saturate their hexapeptide baits, such that a significant proportion of these proteins does not bind (i.e., is depleted) and removed in the flowthrough [1]. Although expected, the high amount of lost protein could be considered as a limitation of this protocol.

It is also important to point out the possible blood contamination of saliva samples, since hemoglobin was detected, although none of the saliva samples used in the present study presented a hemolytic color. In addition, the use of liquid chromatography tandem mass spectrometry (LC-MS/MS) instead of MALDI could have increased the sensitivity of the protein identification, which can be considered another limitation of this study.

\section{Conclusions}

In conclusion, the use of different procedures allowed the detection of different potential stress markers..Untreated saliva as well as the application of a glycoprotein enrichment protocol required only a low amount of saliva sample and provided promising results with modest labour. On the contrary, the use of DRC by hexapeptide libraries prior to 2DE-MS analysis would not be recommended due to the high amount of saliva needed, the complexity of the sample preparation and the large source of potential variability that could be considered as limitations of the procedure.

\section{Abbreviations}

2-DE: Two dimensional electrophoresis; CgA: Chromogranin A; DRC: Dynamic range compression; MS: Mass spectrometry; PBA: Phenyl boronic acid

\section{Acknowledgements}

No applicable.

\section{Funding}

This work was supported by the Spanish Ministry of Economy and Competitiveness [grant number AGL 2012-33,612]; and the European Regional Development Fund.

\section{Availability of data and materials}

The datasets generated and/or analysed during the current study are not publicly available but are available from the corresponding author on reasonable request.

\section{Authors' contributions}

$J J C$ and FT had the original idea and made the study design, sampling and biochemical analyses. AMG, ERF and SS contributed to proteomic analyses. AMG, JJC, ERF, SS and FT contributed to data analyses and preparation of the manuscript. All authors read and approved the final manuscript.

\section{Ethics approval}

All procedures involving animals were approved by the Ethical Committee of the University of Murcia, Spain, and were in accordance to Directive 2010/ 63/EU guidelines.

\section{Competing interests}

Author José Joaquín Cerón is a Section Editor for BMC Veterinary Research. The authors declare that they have no further competing interests.

\section{Publisher's Note}

Springer Nature remains neutral with regard to jurisdictional claims in published maps and institutional affiliations.

\section{Author details}

${ }^{1}$ Department of Animal Medicine and Surgery, Regional Campus of International Excellence "Campus Mare Nostrum", Hospital Veterinario 4 planta, University of Murcia, 30100, Espinardo, Murcia, Spain. ${ }^{2}$ VetCore Facility for Research, University of Veterinary Medicine Vienna, Veterinaerplatz 1, A-1210 Vienna, Austria.

Received: 30 August 2016 Accepted: 22 November 2017

Published online: 04 December 2017

\section{References}

1. Bandhakavi S, Van Riper SK, Tawfik PN, Stone MD, Haddad T, Rhodus NL, Carlis JV, Griffin TJ. Hexapeptide libraries for enhanced protein PTM identification and relative abundance profiling in whole human saliva. J Proteome Res. 2011;10:1052-61.

2. Bonizzi L, Roncada P. Welfare and immune response. Vet Res Commun. 2007;31:97-102.

3. Guzik AC, Matthews JO, Kerr BJ, Bidner TD, Southern LL. Dietary tryptophan effects on plasma and salivary cortisol and meat quality in pigs. J Anim Sci. 2006;84:2251-9.

4. Escribano D, Gutiérrez AM, Tecles F, Cerón JJ. Changes in saliva biomarkers of stress and immunity in domestic pigs exposed to a psychosocial stressor. Res Vet Sci. 2015;102:38-44.

5. Fuentes M, Tecles F, Gutiérrez A, Otal J, Martínez-Subiela S, Cerón JJ. Validation of an automated method for salivary alpha-amylase measurements in pigs (Sus scrofa domesticus) and its application as a stress biomarker. J Vet Diagn Investig. 2011;23:282-7.

6. Fuentes-Rubio M, Cerón JJ, de Torre C, Escribano D, Gutiérrez AM, Tecles F. Porcine salivary analysis by 2-dimensional gel electrophoresis in 3 models of acute stress: a pilot study. Can J Vet Res. 2014;78:127-32.

7. Xu Y, Bailey UM, Punyadeera C, Schulz BL. Identification of salivary Nglycoproteins and measurement of glycosylation site occupancy by boronate glycoprotein enrichment and liquid chromatography/electrospray ionization tandem mass spectrometry. Rapid Commun Mass Spectrom. 2014;28:471-82

8. Krief G, Deutsch O, Zaks B, Wong DT, Aframian DJ, Palmon A. Comparison of diverse affinity based high-abundance protein depletion strategies for improved bio-marker discovery in oral fluids. J Proteome. 2012;75:4165-75.

9. Wang X, Xia N, Liu L. Boronic acid-based approach for separation and immobilization of glycoproteins and its application in sensing. Int J Mol Sci. 2013;14:20890-912.

10. Ahn YH, Kim JY, Yoo JS. Quantitative mass spectrometric analysis of glycoproteins combined with enrichment methods. Mass Spectrom Rev. 2015;34:148-65

11. Henle KJ, Kaushal GP, Nagle WA, Nolen GT. Prompt protein glycosylation during acute heat stress. Exp Cell Res. 1993;207:245-51.

12. Drake PM, Cho W, Li B, Prakobphol A, Johansen E, Anderson NL, Regnier FE, Gibson BW, Fisher SJ. Sweetening the pot: adding glycosylation to the biomarker discovery equation. Clin Chem. 2010;56:223-36.

13. Escribano D, Soler L, Gutiérrez AM, Martínez-Subiela S, Cerón JJ. Measurement of chromogranin A in porcine saliva: validation of a time- 
resolved immunofluorometric assay and evaluation of its application as a marker of acute stress. Animal. 2013;7:640-7.

14. Escribano D, Fuentes-Rubio M, Cerón JJ. Validation of an automated chemiluminescent immunoassay for salivary cortisol measurements in pigs. J Vet Diagn Investig. 2012;24:918-23.

15. Castagna A, Cecconi D, Sennels L, Rappsilber J, Guerrier L, Fortis F, Boschetti E, Lomas L, Righetti PG. Exploring the hidden human urinary proteome via ligand library beads. J Proteome Res. 2005:4:1917-30.

16. Miller I, Crawford J, Gianazza E. Protein stains for proteomic applications: which, when, why? Proteomics. 2006;6:5385-408.

17. Gutiérrez AM, Nöbauer K, Soler L, Razzazi-Fazeli E, Gemeiner M, Cerón J J Miller I. Detection of potential markers for systemic disease in saliva of pigs by proteomics: a pilot study. Vet Immunol Immunopathol. 2013;151:73-82.

18. Gutiérrez AM, Miller I, Hummel K, Nöbauer K, Martínez-Subiela S, RazzaziFazeli E, Gemeiner M, Cerón JJ. Proteomic analysis of porcine saliva. Vet J. 2011;187:356-62.

19. Jiménez CR, Huang L, Qiu Y, Burlingame AL. In-gel digestion of proteins for MALDI-MS fingerprint mapping. Curr Protoc Protein Sci. 2001;14:16.4.1-5.

20. Shevchenko A, Wilm M, Vorm O, Mann M. Mass spectrometric sequencing of proteins from silver-stained polyacrylamide gels. Anal Chem. 1996;68: 850-8.

21. Thaysen-Andersen $M$, Thøgersen IB, Lademann $U$, Offenberg $H$, Giessing AM, Enghild JJ, Nielsen HJ, Brünner N, Højrup P. Investigating the biomarker potential of glycoproteins using comparative glycoprofiling - application to tissue inhibitor of metalloproteinases-1. Biochim Biophys Acta. 2008;1784: 455-63.

22. Ongay S, Boichenko A, Govorukhina N, Bischoff R. Glycopeptide enrichment and separation for protein glycosylation analysis. J Sep Sci. 2012;35:2341-72.

23. Lamy E, Mau M. Saliva proteomics as an emerging, non-invasive tool to study livestock physiology, nutrition and diseases. J Proteome. 2012;75: 4251-8.

24. Ott S, Soler L, Moons CP, Kashiha MA, Bahr C, Vandermeulen J, Janssens S, Gutiérrez AM, Escribano D, Cerón JJ, Berckmans D, Tuyttens FA, Niewold TA. Different stressors elicit different responses in the salivary biomarkers cortisol, haptoglobin, and chromogranin A in pigs. Res Vet Sci. 2014;97:124-8.

25. Flower DR. The lipocalin protein family: structure and function. Biochem J. 1996:318:1-14

26. Hofmann MA, Drury S, Fu C, Qu W, Taguchi A, Lu Y, Avila C, Kambham N, Bierhaus A, Nawroth P, Neurath MF, Slattery T, Beach D, McClary J, Nagashima M, Morser J, Stern D, Schmidt AMRAGE. Mediates a novel proinflammatory axis: a central cell surface receptor for \$100/calgranulin polypeptides. Cell. 1999;97:889-901.

27. Ryckman C, Vandal K, Rouleau P, Talbot M, Tessier PA. Proinflammatory activities of S100: proteins S100A8, S100A9, and S100A8/A9 induce neutrophil chemotaxis and adhesion. J Immunol. 2003;170:3233-42.

28. Baganha MF, Pêgo A, Lima MA, Gaspar EV, Cordeiro AR. Serum and pleural adenosine deaminase - correlation with lymphocytic populations. Chest. 1990:97:605-10

29. Bansal SK, Singh RP, Narang RK, Joshi LD, Bansal A, Agrawal AK. Serum adenosine deaminase in pulmonary tuberculosis, malignancy and nontubercular respiratory disease. Indian J Chest Disease and Allied Sci. 1991;33: 189-93.

30. Kose K, Yazici C, Aşşioğlu O. The evaluation of lipid peroxidation and adenosine deaminase activity in patients with Behcet's disease. Clin Biochem. 2001;34:125-9.

31. Rai B, Kaur J, Jacobs R, Anand SC. Adenosine deaminase in saliva as a diagnostic marker of squamous cell carcinoma of tongue. Clin Oral Investig. 2011;15:347-9.

32. Supuran CT. Carbonic anhydrases: novel therapeutic application for inhibitors and activators. Nat Rev Drug Discov. 2008;7:168-81.

33. Goto T, Shirakawa H, Furukawa Y, Komai M. Decreased expression of carbonic anhydrase isozyme II, rather than of isozyme Vl, in submandibular glands in long-term zinc-deficient rats. Br J Nutr. 2008;99:248-53.

34. Kivelä J, Parkilla S, Parkkila AK, Leinonen J, Rajaniemi H. Salivary carbonic anhydrase isoenzyme VI. Physiol. 1999;520:315-20.

35. Smith CE, Nanci A, Moffatt P. Evidence by signal peptide trap technology for the expression of carbonic anhydrase $V I$ in rat incisor enamel organs. Eur J Oral Sci. 2006;114(Suppl 1):147-53.

36. Tecles F, Contreras-Aguilar MD, Martínez-Miró S, Tvarijonaviciute A, MartínezSubiela S, Escribano D, Cerón JJ. Total esterase measurement in saliva of pigs: validation of an automated assay, characterization and changes in stress and disease conditions. Res Vet Sci. 2017;114:170-6.

37. Hassan MI, Waheed A, Yadav S, Singh TP, Ahmad F. Review: prolactin inducible protein in cancer, fertility and immunoregulation: structure, function and its clinical implications. Cell Mol Life Sci. 2009;66:447-59.

38. Trueba AF, Mizrachi D, Auchus RJ, Vogel PD, Ritz T. Effects of psychosocial stress on the pattern of salivary protein release. Physiol Behav. 2012;105: 841-9.

39. Van Nieuw Amerongen AV, Bolscher JG, Veerman ECl. Salivary proteins: protective and diagnostic value in cariology? Caries Res. 2004;38:247-53.

40. Matos-Gomes N, Katsurayama M, Makimoto FH, Santana LL, Paredes-Garcia E, Becker MA, Dos-Santos MC. Psychological stress and its influence on salivary flow rate, total protein concentration and $\lg \mathrm{A}$, $\lg \mathrm{G}$ and $\lg \mathrm{M}$ titers. Neuroimmunomodulation. 2010;17:396-404.

41. Redegeld FA, Thio M, Groot Kormelink T. Polyclonal immunoglobulin free light chain and chronic inflammation. Mayo Clin Proc. 2012;87:1032-3.

42. Heaney JL, Gleeson M, Phillips AC, Taylor IM, Drayson MT, Goodall M, He CS, Svendsen IS, Killer SC, Campbell JP. Salivary immunoglobulin free light chains: reference ranges and responses to exercise in young and older adults. Exerc Immunol Rev. 2016;22:28-41.

43. Liu YC, Chen CJ. A Rapid Approach for Fabricating Boronic AcidFunctionalized Plates for On-Probe Detection of Glycoprotein and Glycopeptide. Mass Spectrom (Tokyo). 2017;6:S0063.

\section{Submit your next manuscript to BioMed Central and we will help you at every step:}

- We accept pre-submission inquiries

- Our selector tool helps you to find the most relevant journal

- We provide round the clock customer support

- Convenient online submission

- Thorough peer review

- Inclusion in PubMed and all major indexing services

- Maximum visibility for your research

Submit your manuscript at www.biomedcentral.com/submit
Biomed Central 